\title{
Segmented Liquid Crystalline Copolymers and Blending with Engineering Plastics
}

\author{
Qing YAN and Jiasong $\mathrm{HE}$ \\ State Key Laboratory of Engineering Plastics \\ Institute of Chemistry, Academia Sinica \\ Beijing 100080, China
}

(Received February 14, 1994)

\begin{abstract}
Two series of segmented copolyesters were synthesized, in which the flexible blocks were poly(ethylene terephthalate) (PET) and the hard blocks were fully aromatic triads as mesogens. The copolymers maintained the ability to form a mesophase at temperatures above the melting points when they contained only $12 \%$ equivalent $p$-hydroxyl benzoate (PHB) moiety as in PHB/PET random copolymer. With increasing length of the PET segments in the copolymers, their compatibility with PET matrix in blending was improved better than normal liquid crystalline polymers (LCPs) for in-situ composites. Some mechanical properties of the polyblends were primarily measured for potential usage in this respect.

KEY WORDS Liquid Crystalline Polymer / Flexible Spacer / in-situ Composite / Block Copolymer / Compatibility / Miscibility /
\end{abstract}

Using liquid crystalline polymers (LCPs), especially thermotropic liquid crystalline polymers (TLCPs), as engineering plastics leads to high-performance materials with a good processability. However, because of the relative high price, large scale applications of pure LCPs are still rare. Just for economical reasons, people have been thinking about blending LCPs with ordinary materials since the beginning of LCP development. In the late 70's, Helminiak $^{1}$ and Takayanagi ${ }^{2}$ independently proposed a concept of "molecular composite", which is derived from the composites made of macro-fibers (i.e., glass fibers or carbon fibers) and polymeric matrices. The ideal is to disperse stretched rod-like LCP molecules at the molecular level into materials of practical use, just like macro-fibers in traditional composites. But this goal is difficult to achieve even under optimum conditions of solution mixing, because it is thermodynamically unfavorable.

A more realistic proposal was put forth with the development of thermotropic LCPs: if a
TLCP is blended with thermoplastics in the molten state during processing, it is expected to get a material in which LCP fibrils are aligned in the flow direction. ${ }^{3,4}$ Because the reinforcement of LCP forms in-situ during processing, the resulted materials are referred to as "in-situ composites". Two things are of primary importance for the success of in-situ composites. First, the TLCPs have to be dispersed into the matrices evenly and finely, and the resulting two phase morphology should have an intimate boundary for efficient stress transfer. Secondly, the dispersed TLCP domains should have a high aspect ratio and good alignment to take full advantage of the fiber-like reinforcement. In the first case, compatibility of the TLCP with matrix material is crucial. This suggests that the more flexible the LCP chain, the better the dispersion. By contrast, the second condition can only be fulfilled when LCP chains are stiff enough to keep the rod-like shape in a vigorous flow field during blending and processing and make the 
TLCP domains take the shape of fibrils.

Most works on blending of TLCPs with thermoplastics so far in the literature are industry oriented. Considerable data have accumulated, but deviations, and sometimes contrarieties, also occurred among these data. This is understandable considering the sensitivity of LCPs to processing parameters. The mechanical properties of the blends are usually poor, or at least not as good as expected.

There are a few patents and papers, which involved corporation of selected flexible chain blocks into the TLCPs, show some encouraging results recently. ${ }^{5-12}$ TLCPs with really regular structures are difficult to obtain. They need very careful and delicate synthesis work. Nevertheless, to fully understand the relationship between structure and properties in in-situ composites, it is necessary to be able to control and modify the molecular structure of TLCPs. For this purpose, the authors prepared semi-regular segmented molecules with some chain parameters adjustable. The target compounds are schematically shown below:

in which the flexible spacer is an oligomer poly(ethylene terephthalate) (PET) block with different average chain lengths and the mesogenic units are chosen from different conjugated aromatic rings. In the first stage of the study, only three-ring hard blocks (triad) were involved.

\section{EXPERIMENTAL}

\section{Materials}

Terephthaloyl chloride (TPC) was prepared from terephthalic acid by reaction with thionyl chloride in the presence of catalyst amount of $N, N$-dimethylformamide (DMF). Bis(hydroxyethyl) terephthalate (BHET), the "monomer" of PET, was prepared by transesterification between ethylene glycol and dimethyl terephthalate (DMT) at no more than $200^{\circ} \mathrm{C} .{ }^{13}$

All other starting materials and solvents were obtained commercially. They were used as received without further purification, except as mentioned specifically in the Syntheses Section for some strictly dehydrous processes.

\section{Syntheses}

Two compounds with minor differences in mesogenic units have been synthesized with different strategies:

\section{Synthesis Method I ${ }^{14}$}
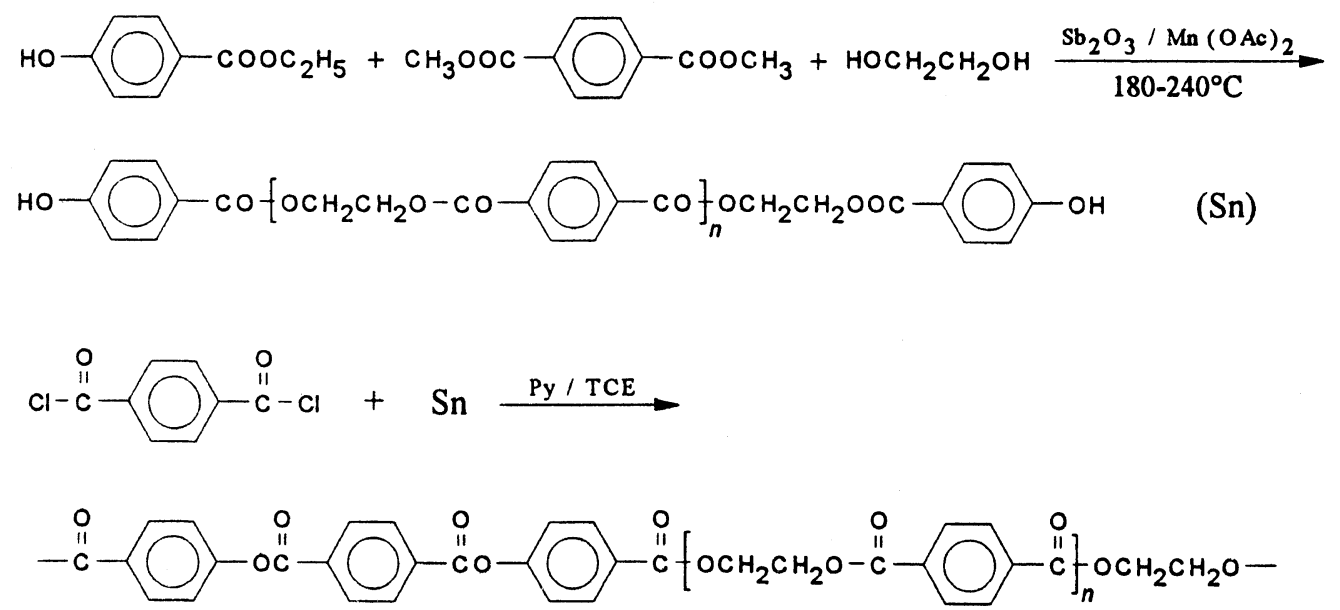
A desired amount of ethyl $p$-hydroxybenzoate (EtHB) was added into a reaction vessel with BHET and ethylene glycol (EG) for ester exchange condensation. In the presence of catalysts $\mathrm{Sb}_{2} \mathrm{O}_{3}$ and $\mathrm{Mn}(\mathrm{OAc})_{2}$, the reaction was carried out at high temperature increased stepwise from $180^{\circ} \mathrm{C}$ to $240^{\circ} \mathrm{C}$ for $4-6$ hours. ${ }^{14}$ Vacuum was applied at the last stage to remove the condensed EG as thoroughly as possible. ${ }^{14}$
The phenol hydroxyl terminated oligomers subsequently reacted stoichiometrically with terephthaloyl chloride (TPC) in tetrachloroethane (TCE) solution in the presence of pyridine (Py) to form a polymer with triad mesogenic segments: ---T-HB-T--- linked by PET spacer along the chain.

\section{Synthesis Method II}
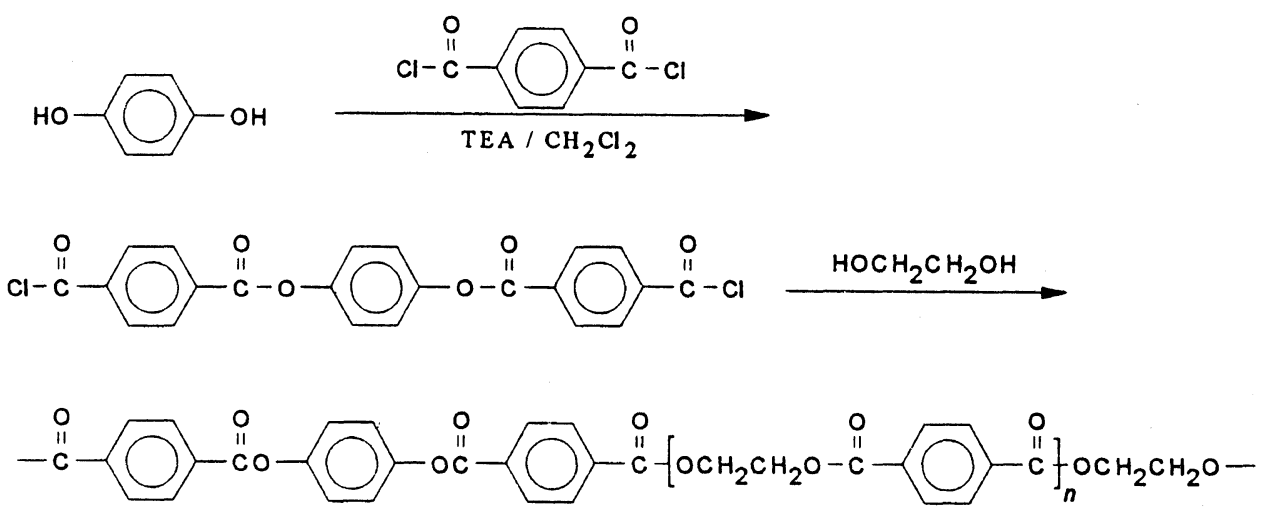

Hydroquinone (HQ) reacted with excess TPC in solution before stoichiometrical EG (with the excessive TPC) was added after 24 hours. A typical process for the preparation of $\mathrm{HQ}(4)(n=4)$ is as follows: $20.3 \mathrm{~g}$ TPC $(0.1 \mathrm{~mol})$ dissolved in $150 \mathrm{ml}$ dichloromethane $\left(\mathrm{CH}_{2} \mathrm{Cl}_{2}\right)$ in a $500 \mathrm{ml}$ 3-necked flask. A solution of $1.83 \mathrm{~g} \mathrm{HQ}(0.0167 \mathrm{~mol})$ in $60 \mathrm{ml}$ and $50 \mathrm{ml}$ triethylamine (TEA) was drop in when the reaction mixture was cooled with ice-water. $5.17 \mathrm{~g} \mathrm{EG}(0.0833 \mathrm{~mol})$ was added together with $10 \mathrm{ml} \mathrm{TEA}$ and $50 \mathrm{ml} \mathrm{CH}_{2} \mathrm{Cl}_{2} 24$ hours later. The reaction continued for another 24 hours to completion. A polymer with the dominant triad hard segment ---HQ-T-HQ--- was precipitated and collected from acetone or methanol.

\section{Measurement and Characterization}

Inherent viscosities $\eta_{\text {inh }}\left(0.5 \mathrm{~g} \mathrm{dl}^{-1}\right)$ were measured in $1: 1(\mathrm{w} / \mathrm{w})$ phenol/o-dichlorobenzene at $25^{\circ} \mathrm{C}$. Some copolymers with high mesogen content failed to dissolve in this mixed solvent.
Chemical compositions and chain sequences of the copolymers were determined by ${ }^{1} \mathrm{H}$ NMR spectra obtained from Varian UNITY200 spectrometer, using deuterized trifluoroacetic acid as the solvent at ambient temperature.

Sample blending and injection of the TLCP with PET were prepared in a CS-183 Mini Max molder from the Custom Scientific Instrument Inc. at $270^{\circ} \mathrm{C}$ for 3 minutes to minimize the inter-chain trans-esterification reaction between the LC segments as well as between the TLCP and PET. ${ }^{16}$ The molded species of $75 \times$ $12.36 \times 3.10 \mathrm{~mm}^{3}$ was tested in an Instron 1122 for mechanical properties.

Optical texture and melting behavior were observed on a hot-stage with a Carl-Zeiss PHMK 80/2603 cross-polarized microscope up to the temperature of $350^{\circ} \mathrm{C}$. The thermal properties of the copolymers and polyblends were also studied on a Perkin-Elmer DSC7 differential scanning calorimeter. All samples were first pre-heated to $300^{\circ} \mathrm{C}$ at a rate of 
$50^{\circ} \mathrm{Cmin}^{-1}$ and kept at that temperature for 3 minutes before any further scanning.

The morphology of the TLCP and their blends with PET were photographed with a Hitachi S-530 Scanning Electronic Microscope.

\section{RESULTS AND DISCUSSION}

\section{Synthetic Work}

In the oligomer stage of Synthesis Method I, since condensation was carried out at high temperature, there are several rival reactions competitively co-existing:

1. Participation of phenol group in hydroxybenzoate (HB) to form a segment like

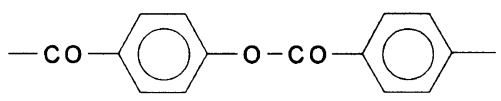

2. Etherification of the phenol group with ethylene glycol (EG) to form a segment like

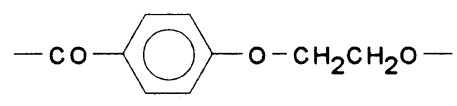

The first reaction creates an extra mesogenic unit of two conjugated rings (dyad), whereas the second one wastes an HB group with no contribution to mesogens formation. Both make a movement of HB group from the chain ends to the middle of the oligomer chains. This will in turn destroy the chain regulation in the next step of the triad hard segment formation.

The first side reaction can be successfully suppressed by limiting the reaction temperature to no more than $250^{\circ} \mathrm{C} .{ }^{15}$ But control of the second reaction has proved hard, because the etherification and esterification reactions require very similar conditions. Some acid catalysts were used to get better results, but the amounts of formed ether groups were still appreciable in NMR spectrum. Direct esterification of terephthalic acid with ethylene glycol was also done with no success.

\section{Characterization}

NMR is useful for copolymer chain sequence analyses. From spectra of monomers and a model compound:

$$
\mathrm{CH}_{3} \mathrm{CH}_{2} \mathrm{OCO} O-\mathrm{OCO} O-\mathrm{COO}-\mathrm{O}-\mathrm{COOCH}_{2} \mathrm{CH}_{3}
$$

the chemical shifts of oligomers in the $\operatorname{HB}(n)$ series (from Synthesis Method I) were assigned accurately:<smiles>COc1ccc(C=O)cc1</smiles>

$$
\delta=8.25
$$

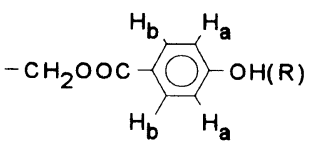

$\delta=7.05\left(\mathrm{H}_{\mathrm{a}}\right), 8.10\left(\mathrm{H}_{\mathrm{b}}\right)$
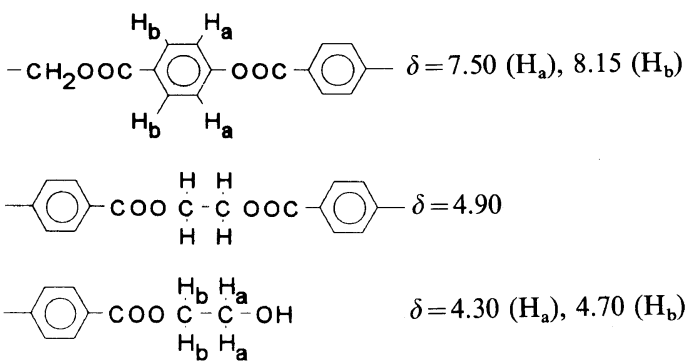

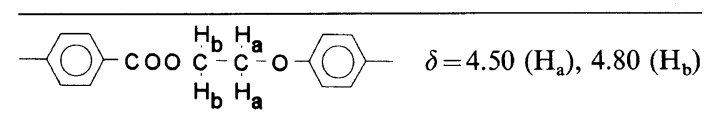

No peaks around $\delta=7.5$ were detected, and this confirms that the phenolic hydroxyl group is well kept out of the esterification reaction (side reaction 1). But the ether peak at $\delta=$ 4.5 notably presented (Figure 1). Acid catalyst added and direct esterification from terephthalic acid can depress this peak to some extent, but never completely (side reaction 2).

For copolymers from $\mathrm{HQ}(n)$ series (Synthesis Method II), hard segment chain distribution can also be traced by NMR spectroscopy, and the average chain length can be calculated. In this case, the terephthalate moiety $(\mathrm{T})$ can be attached at both ends by hydroquinone (A) or ethylene glycol (B). Three possibilities should be considered: ${ }^{17}$ 


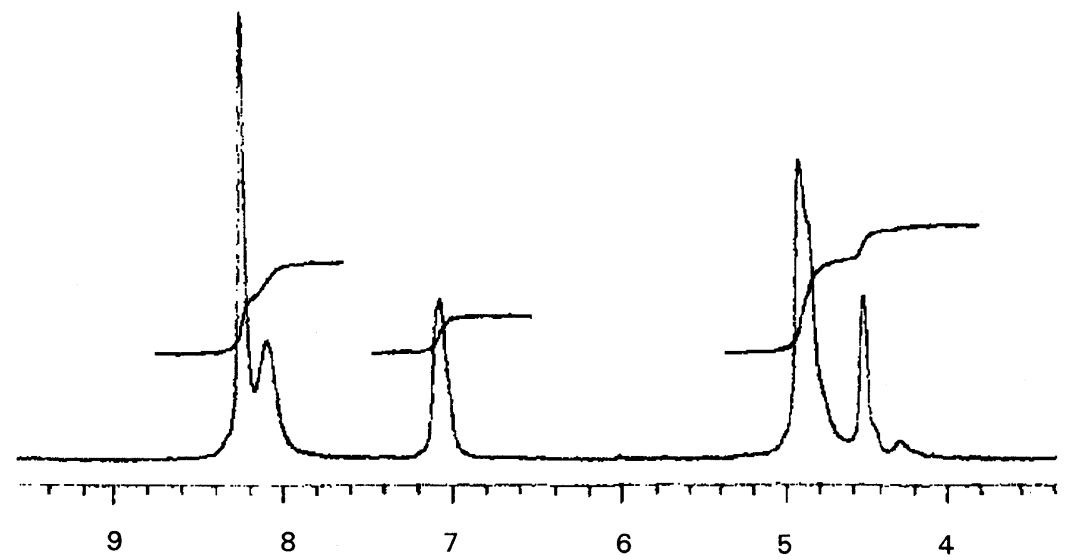

Figure 1. NMR spectrum of Oligomers $\mathrm{S}_{\mathrm{n}}$ in the $\mathrm{HB}(n)$ series $(n=2)$.<smiles>COc1ccc(OC(=O)c2ccccc2C(=O)Oc2ccc(OC#[Al+2])cc2)cc1</smiles>

$\delta=8.45$<smiles>COCCOC(=O)c1ccc(C(=O)OCCOCBr)cc1</smiles>

$\delta=8.18$

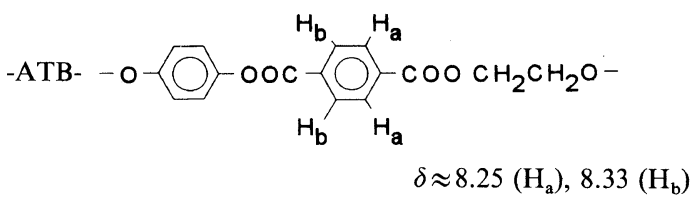

From the spectrum in Figure 2, the relative area under each peak, i.e., $P_{\mathrm{ATA}}, P_{\mathrm{BTB}}$, and $P_{\text {ATB }}$, is available. According to the statistic theory of chain construction, the microstructure parameters of the chain can be determined from these data.

Probability of an AT unit linked by a BT unit:

$$
P_{\mathrm{AB}}=P_{\mathrm{ATB}} /\left(2 P_{\mathrm{ATA}}+P_{\mathrm{ATB}}\right)
$$

Probability of a BT unit linked by an AT unit:

$$
P_{\mathrm{BA}}=P_{\mathrm{ATB}} /\left(2 P_{\mathrm{BTB}}+P_{\mathrm{ATB}}\right)
$$

Thus the mean sequence lengths $\left\langle\mathrm{L}_{\mathrm{A}}\right\rangle$ and

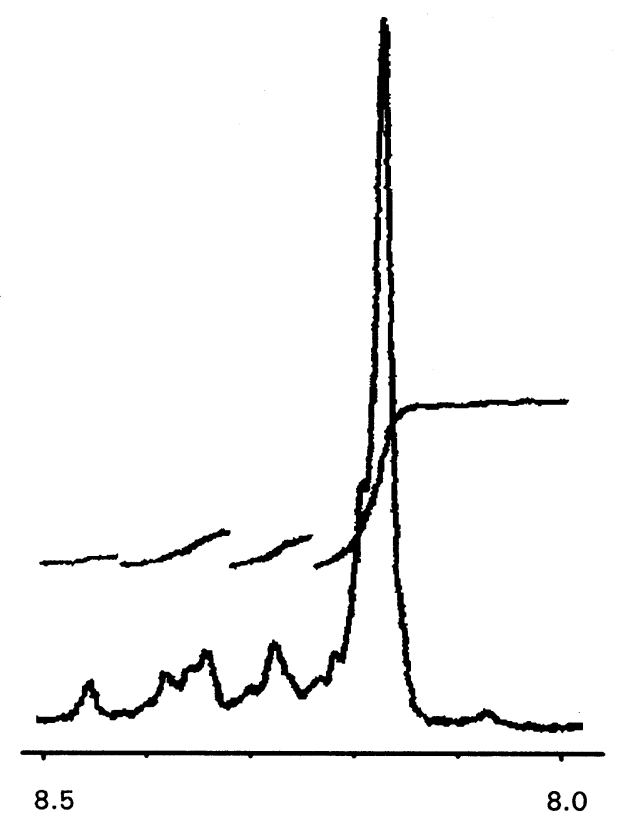

Figure 2. Portion of the NMR spectrum of an $\mathrm{HQ}(n)$ series copolymer $(n=4)$.

$\left\langle\mathrm{L}_{\mathrm{B}}\right\rangle$ are available:

$$
\begin{aligned}
& \left\langle\mathrm{L}_{\mathrm{A}}\right\rangle=1 / P_{\mathrm{AB}}, \\
& \left\langle\mathrm{L}_{\mathrm{B}}\right\rangle=1 / P_{\mathrm{BA}} .
\end{aligned}
$$

If the hard segment is uniform triad, every -ATA- unit should be isolated by at least one -B- block. The ideal value of $P_{\mathrm{AB}}$ should thus be exactly $100 \%$, the $\left\langle\mathrm{L}_{\mathrm{A}}\right\rangle 1$. From the results 
in Table I, with increasing $n$, the triad becomes dominant.

\section{Liquid Crystallinity}

Properties of the $\mathrm{HB}(n)$ copolymer series were discussed in a previous paper. ${ }^{14}$ Table II summarizes the main properties of the block copolymers from the $\mathrm{HQ}(n)$ series. The products are of rather low molecular weight by inherent viscosities. Contrary to random copolymers of $p$-hydroxyl benzoate (PHB)/ PET, which become isotropic when the content of PHB component is less than $20 \%$, this series of copolymers shows birefringence above the melting temperature, i.e., they are thermotropic liquid crystalline even when the equivalent PHB content is as low as about $10 \%$. The texture of the mesophase observed by polarized microscope is a two-phase system. ${ }^{14}$ The nature of the ordering phase is unclear. With increase of spacer length, the birefrigence of the mesophase domain gets weaker and weaker, and the portion of the mesophase smaller and

Table I. Characterization of the $\mathrm{HQ}(n)$ copolymer series by the synthsis Method II

\begin{tabular}{llllll}
\hline \multicolumn{1}{c}{ Sample } & $\mathrm{HQ}(1)$ & $\mathrm{HQ}(2)$ & $\mathrm{HQ}(4)$ & $\mathrm{HQ}(8)$ & $\mathrm{HQ}(14)$ \\
\hline Spacer length $(n)^{\mathrm{a}}$ & 1.19 & 1.64 & 4.59 & 8.77 & 14.70 \\
$\left\langle\mathrm{~L}_{\mathrm{A}}\right\rangle$ & 1.52 & 1.23 & 1.28 & 1.06 & 1.12 \\
$\eta_{\text {inh }} / \mathrm{dl} \mathrm{g}^{-1}$ & $\mathrm{~N} / \mathrm{A}^{\mathrm{b}}$ & 0.102 & 0.123 & 0.109 & - \\
\hline
\end{tabular}

a Calculated from relative amounts of EG and HQ.

b Undissolvable. smaller. No isotropic transitions were observed up to $350^{\circ} \mathrm{C}$.

DSC results show the same trends for the temperature of melting $\left(T_{\mathrm{m}}\right)$ and of solidification $\left(T_{\mathrm{c}}\right)$. When the spacer length increases from $n=1$ to $n=4, T_{\mathrm{m}}$ descreases from over $300^{\circ} \mathrm{C}$ to about $230^{\circ} \mathrm{C}$ (according to literatures, $T_{\mathrm{m}}>500^{\circ} \mathrm{C}$ when $n=0$ ); further increase in spacer length leads to slight increase of $T_{\mathrm{m}}$ approaching the value of pure PET (Figure 3). An interesting thing is that the heat of fusion and heat of solidification increase steadily with increasing spacer length. This is because the hard segment is too stiff to fold into crystallites, as in case of full-aromatic TLCPs no peaks of melt nor of solidification can be identified from the DSC thermogram. ${ }^{18}$

\section{Blending with PET}

Since the chain structure of the $\operatorname{HB}(n)$ se-

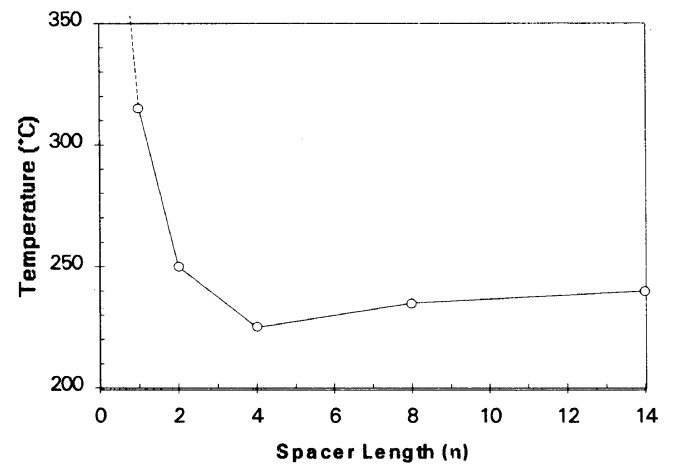

Figure 3. $T_{\mathrm{m}}$ versus spacer lengths of $\mathrm{HQ}(n)$ series copolymers.

Table II. Properties of HQ(n) series block copolymers

\begin{tabular}{|c|c|c|c|c|c|}
\hline & $\mathrm{HQ}(1)$ & $\mathrm{HQ}(2)$ & $\mathrm{HQ}(4)$ & $\mathrm{HQ}(8)$ & HQ(14) \\
\hline Molar ratio of hard segment & 50.0 & 37.5 & 25.0 & 15.0 & 9.4 \\
\hline Equivelent $\mathrm{PHB} \%$ as in $\mathrm{PHB} / \mathrm{PET}$ & 50.0 & 14.0 & 28.6 & 18.2 & 11.8 \\
\hline$T_{\mathrm{c}}{ }^{\circ} \mathrm{C}$ (onset) ${ }^{\mathrm{a}}$ & - & 204.6 & 186.1 & 190.0 & 193.5 \\
\hline$\Delta H_{\mathrm{c}} / \mathrm{J} \mathrm{g}^{-1}$ & - & 11.65 & 36.60 & 45.24 & 50.43 \\
\hline$T_{\mathrm{m}}{ }^{\circ} \mathrm{C}(\text { peak })^{\mathrm{b}}$ & - & 252.6 & 240.8 & 245.6 & 249.5 \\
\hline$\Delta H_{\mathrm{f}} / \mathrm{Jg}^{-1}$ & - & 6.11 & 36.25 & 45.19 & 49.04 \\
\hline$T_{\mathrm{m}}{ }^{\circ} \mathrm{C}$ (visual) ${ }^{\mathrm{c}}$ & $\approx 315$ & $240-260$ & $220-225$ & $235-240$ & $235-240$ \\
\hline
\end{tabular}

a Solidification temperature measured by cooling at $-50^{\circ} \mathrm{Cmin}^{-1}$.

b Melting temperature measured by heating at $50^{\circ} \mathrm{C} \mathrm{min}^{-1}$.

c Observed on hot-stage by optical microscope. 

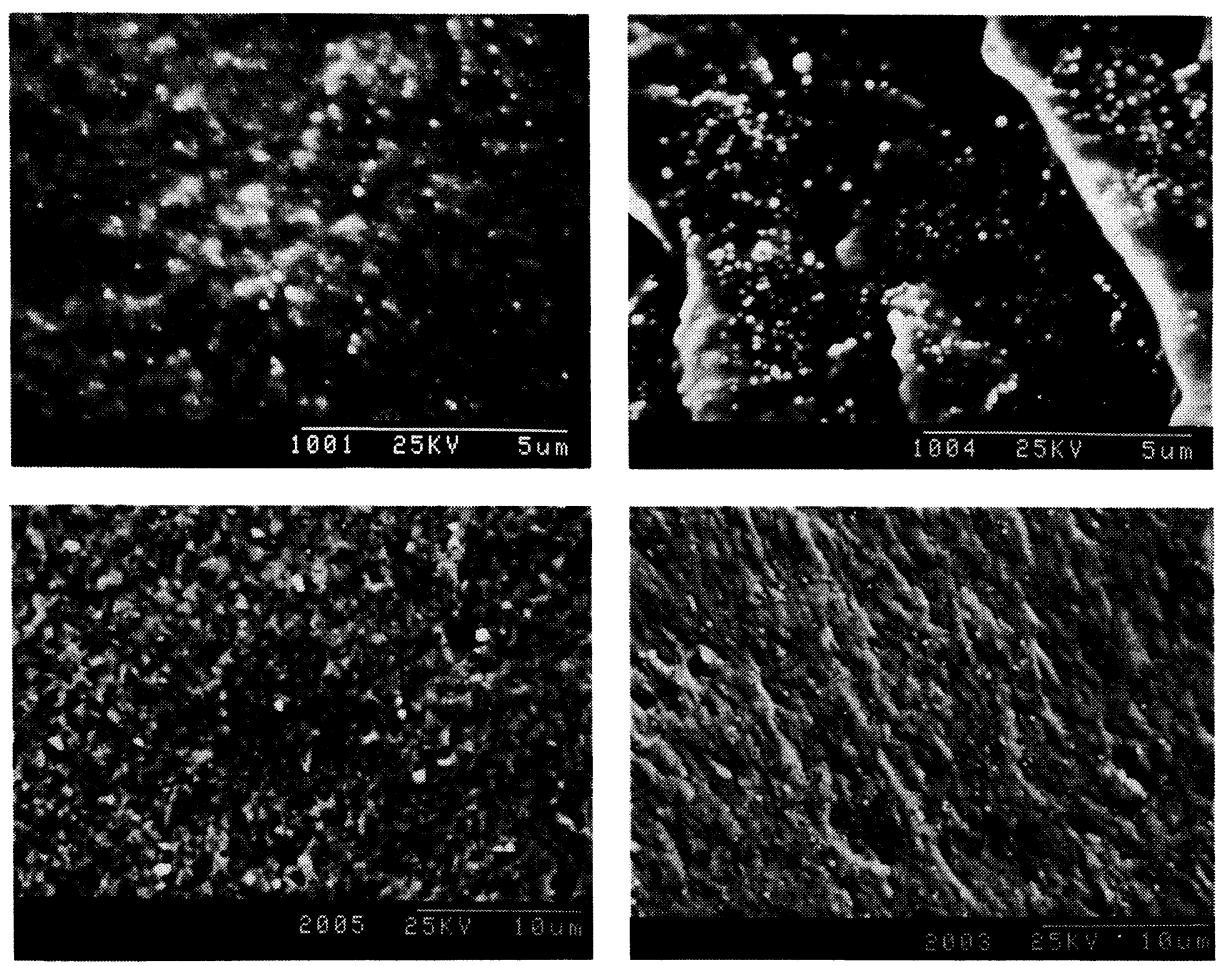

Figure 4. SEM Photographs for morphology study. a, pure PET; b, PET containing 10.7\% HQ(4); c, PET containing $60 \% \mathrm{HQ}(4)$; d, pure $\mathrm{HQ}(4)$.

ries copolymers was not as regular as expected, only the HQ $(n)$ TLCP series was blended with PET for examination. When $n=1$ or 2, the dispersion was obviously inhomogeneous possibly due to the high viscosity of the LCP melt at the processing temperature of PET. Electronic microscopy (SEM) (Figure 4) showed that for the copolymers containing a PET spacer with $n \geq 4$, "homogeneity" is retained up to $10 \mathrm{wt} \% \mathrm{LCP}$, i.e., no phase separation was observed on a $100 \mathrm{~nm}$ scale. With further increase of LCP content, phase separation does occur, but the dispersed domains are very fine (no larger than $0.5 \mu \mathrm{m}$ with $60 \%$ LCP). This means that certain lengths of PET blocks in the HQ $(n)$ LCPs promote compatibility between the TLCP and matrix PET.

Table III shows the results of thermal analysis. The low molecular weight LCP,
Table III. DSC Results for PET containing different amounts of $\mathrm{HQ}(4) \mathrm{LCP}$

\begin{tabular}{lccccc}
\hline Sample & PET & $\# 1$ & $\# 2$ & $\# 3$ & LCP \\
\hline LCP wt $\%$ & 0 & 10.7 & 37.5 & 60.0 & 100 \\
$T_{\mathrm{c}}{ }^{\circ} \mathrm{C}$ (onset) & 194.5 & 202.5 & 192.8 & 188.8 & 186.1 \\
$\Delta H_{\mathrm{c}} / \mathrm{Jg}^{-1}$ & 46.49 & 53.31 & 49.24 & 47.63 & 36.60 \\
$T_{\mathrm{m}}{ }^{\circ} \mathrm{C}$ (peak) & 261.2 & 258.1 & 255.4 & 247.5 & 240.8 \\
$\Delta H_{\mathrm{f}} / \mathrm{Jg}^{-1}$ & 45.39 & 48.44 & 46.61 & 46.04 & 36.25 \\
\hline
\end{tabular}

HQ(4), depresses the melting point of PET linearly, but increases the temperature of crystallization when PET is the main component (Figure 5). The heat of crystallization $\left(\Delta H_{\mathrm{c}}\right)$ and heat of fusion $\left(\Delta H_{\mathrm{f}}\right)$ also increase when a small amount of the LCP is added, whileas LCP itself has an even lower value than PET. This promotion of the crystallization and crystallinity of PET is parallel to the results from many other research groups. As sug- 


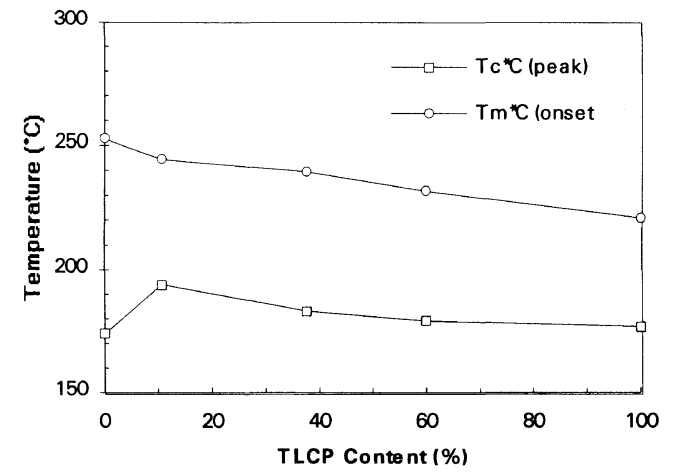

Figure 5. $T_{\mathrm{m}}$ and $T_{\mathrm{c}}$ of PET containing different amounts of thermotropic liquid crystalline polymers (TLCP).

Table IV. PET containing an equivalent amount of hard segment $(2.3 \mathrm{wt} \%)$ from a different $\mathrm{HQ}(n)$

\begin{tabular}{lccc}
\hline & $\mathrm{HQ}(2)$ & $\mathrm{HQ}(4)$ & $\mathrm{HQ}(8)$ \\
\hline LCP wt $\%$ & 7.4 & 10.7 & 18.0 \\
$T_{\mathrm{c}}{ }^{\circ} \mathrm{C}$ (onset) & 205.2 & 202.5 & 202.1 \\
$\Delta H_{\mathrm{c}} / \mathrm{J} \mathrm{g}^{-1}$ & 53.97 & 53.31 & 48.13 \\
$T_{m}{ }^{\circ} \mathrm{C}$ (peak) & 247.3 & 258.1 & 255.1 \\
$\Delta H_{\mathrm{f}} / \mathrm{Jg}^{-1}$ & 47.73 & 48.44 & 44.32
\end{tabular}

Table V. Mechanical properties of PET and blends with $\mathrm{HQ}(n)$ TLCPs

\begin{tabular}{ccccc}
\hline Sample & PET & $\begin{array}{c}1 \% \\
\text { HQ(4) }\end{array}$ & $\begin{array}{c}1 \% \\
\text { HQ(8) }\end{array}$ & $\begin{array}{c}1 \% \\
\text { HQ(14) }\end{array}$ \\
\hline Flexible strength/MPa & 45.9 & 51.9 & 53.4 & 45.0 \\
Flexible modulus/GPa & 2.20 & 2.52 & 2.61 & 2.60 \\
$\begin{array}{c}\text { Maximum elongation } \\
\text { /mm mm }\end{array}$ & 0.020 & 0.023 & 0.024 & 0.024 \\
& & & &
\end{tabular}

gested, a nucleating effect of LCP may take the responsibility. ${ }^{19}$ Further study on the nucleating effect of the TLCP series with different spacer lengths shows that with the same amount of hard segment presented in the blend, LCP with higher hard segment content has greater effect (Table IV).

Mechanical properties were also measured for samples of PET containing 1\% different $\mathrm{HQ}(n)$. The results show that small amounts of TLCPs, even with low molecular weight, improve the strength and stiffness of PET plastics marginally (Table V). This may be due to the enhanced PET crystallinity caused by the small amount TLCPs added (Table III), as well as reinforcement from the TLCP molecules with better compatibility with PET matrix.

\section{CONCLUSIONS}

With a relatively easy synthetic strategy, segmented copolyesters containing mesogenic hard segments and PET spacers were obtained. The semi-regular chain structure of the resulted material has a stronger inclination to form the anisotropic meso-phase upon melting than a random copolymer with the same composition. As expected, certain length PET blocks along the main chain promote the compatibility of the TLCP with PET matrix.

As reported in previous works, the possibility to have a stable mesophase and properties of the formed mesophase strongly depend on the lengths (or axial ratios) of the conjugated rings and nature of interlinks between the rings of hard segment. The effects of different hard blocks on the obtained TLCPs and consequent blending will be studied.

Acknowledgment. This work was supported by National Natural Science Foundation of China (NSFC).

\section{REFERENCES}

1. T. E. Helminiak, F. E. Arnold, and C. L. Benner, Polym. Prepr., Am. Chem. Soc., Div. Polym. Chem., 16, 659 (1975).

2. M. Takayanagi, T. Ogata, M. Morikawa, and T. Kai, J. Macromol. Sci. Phys., B17, 591 (1980).

3. G. Kiss, Polym. Eng. Sci., 27, 410 (1987).

4. A. I. Isayev and M. Modic, Polym. Composites, 8, 158 (1987).

5. D. Melot and W. J. MacKnight, Polym. Adv. Technol., 3, 383 (1992).

6. S. Dashevsky, K. S. Kim, S. W. Palmaka, R. L. Johnston, L. A. G. Busscher, and J. A. Juijin, PCT Int. Appl. WO 93 13,172 (Cl. C08L67/02), US Appl. Patent 812,606, December 23, 1991.

7. S. Dashevsky, K. S. Kim, and S. W. Palmaka, PCT 
Int. Appl. WO 93 13,173 (Cl. C08L67/02), US Appl. Patent 812,607, December 23, 1991.

8. Y. G. Lin, H. W. Lee, H. H. Winter, S. Dashevsky, and K. S. Kim, Polymer, 34, 4703 (1993).

9. T. Kobayashi, M. Sato, N. Takano, and K. Mukaida, Eur. Polym. J., 29, 1625 (1993).

10. T. Galcera, A. Fradet, and E. Marechal, Makromol. Chem. Macromol. Symp., 64, 33 (1992).

11. W. Heitz, W. Brenda, G. Heyde, and T. Wallach, Polym. Prepr., 33, 201 (1992).

12. A. S. Angeloni, M. C. Bignozzi, M. Laus, E. Chiellini, and G. Galli, Polym. Bull., 31, 387 (1993).
13. K. Tomita, Polymer, 17, 221 (1976).

14. Yan Qing and He Jiasong, Polym. Bull., 29, 633-638 (1992).

15. R. K. Quisenberry (to E. I. du Pont), US Patent 3,316,326; Chem. Abstr., 67: 3635e (1967).

16. F. M. Li, H. X. Zhou, and T. Sun, Acta Polymerica Sinica, 2, 189 (1993).

17. H. Zhang, X. Ning, P. Wang, Z. Zhang, and Z. Guan, Makromol. Chem., 189, 1987 (1988).

18. J. He, W. Bu, H. Zhang, P. Xie, and X. Xu, International Polymer Processing, 8, 129 (1993).

19. J. He, H. Zhang, Q. Yuan, and G. Li, Acta Polymerica Sinica, 5, 599 (1992). 